\title{
Influences of Molecular Weights on Physicochemical and Biological Properties of Collagen-Alginate Scaffolds
}

\author{
Truc Cong Ho ${ }^{1,+}{ }^{+}$Jin-Seok Park ${ }^{2,+} \oplus$, Sung-Yeoul Kim ${ }^{2}$, Hoyeol Lee ${ }^{3}$, Ju-Sop Lim ${ }^{4}$, Shin-Jun Kim ${ }^{4}$, \\ Mi-Hee Choi ${ }^{4}{ }^{(}$, Seung Yun Nam ${ }^{5}$ and Byung-Soo Chun ${ }^{2, *}$ \\ 1 Institute of Food Science, Pukyong National University, 45 Yongso-ro, Nam-gu, Busan 48513, Korea; \\ hocongtruc@pukyong.ac.kr \\ 2 Department of Food Science and Technology, Pukyong National University, 45 Yongso-ro, Nam-gu, \\ Busan 48513, Korea; jin1931@pukyong.ac.kr (J.-S.P.); kim41409114@pukyong.ac.kr (S.-Y.K.) \\ 3 Industry 4.0 Convergence Bionics Engineering, Pukyong National University, Busan 48513, Korea; \\ lhy950@pukyong.ac.kr \\ 4 PL MICROMED Co., Ltd., 1F, 15-5, Yangju 3-gil, Yangsan-si, Gyeongsangnam-do 50620, Korea; \\ casseur1@plmicromed.com (J.-S.L.); shinjun@plmicromed.com (S.-J.K.); \\ mhchoi28@plmicromed.com (M.-H.C.) \\ 5 Department of Biomedical Engineering, Pukyong National University, Busan 48513, Korea; \\ synam@pknu.ac.kr \\ * Correspondence: bschun@pknu.ac.kr; Tel.: +82-51-629-5830 \\ + The two authors contributed equally.
}

Citation: Ho, T.C.; Park, J.-S.; Kim, S.-Y.; Lee, H.; Lim, J.-S.; Kim, S.-J.; Choi, M.-H.; Nam, S.Y.; Chun, B.-S. Influences of Molecular Weights on Physicochemical and Biological Properties of Collagen-Alginate Scaffolds. Mar. Drugs 2021, 19, 85. https://doi.org/10.3390/md19020085

Academic Editor: Sik Yoon

Received: 29 December 2020

Accepted: 28 January 2021

Published: 2 February 2021

Publisher's Note: MDPI stays neutral with regard to jurisdictional claims in published maps and institutional affiliations.

Copyright: (c) 2021 by the authors. Licensee MDPI, Basel, Switzerland. This article is an open access article distributed under the terms and conditions of the Creative Commons Attribution (CC BY) license (https:// creativecommons.org/licenses/by/ $4.0 /)$

\begin{abstract}
For tissue engineering applications, biodegradable scaffolds containing high molecular weights (MW) of collagen and sodium alginate have been developed and characterized. However, the properties of low MW collagen-based scaffolds have not been studied in previous research. This work examined the distinctive properties of low MW collagen-based scaffolds with alginate unmodified and modified by subcritical water. Besides, we developed a facile method to cross-link water-soluble scaffolds using glutaraldehyde in an aqueous ethanol solution. The prepared cross-linked scaffolds showed good structural properties with high porosity ( 93\%) and high cross-linking degree (50-60\%). Compared with collagen (6000 Da)-based scaffolds, collagen (25,000 Da)-based scaffolds exhibited higher stability against collagenase degradation and lower weight loss in phosphate buffer $\mathrm{pH}$ 7.4. Collagen (25,000 Da)-based scaffolds with modified alginate tended to improve antioxidant capacity compared with scaffolds containing unmodified alginate. Interestingly, in vitro coagulant activity assay demonstrated that collagen (25,000 Da)-based scaffolds with modified alginate (C25-A63 and C25-A21) significantly reduced the clotting time of human plasma compared with scaffolds consisting of unmodified alginate. Although some further investigations need to be done, collagen (25,000 Da)-based scaffolds with modified alginate should be considered as a potential candidate for tissue engineering applications.
\end{abstract}

Keywords: low molecular weight collagen; subcritical water modified alginate; scaffolds; physicochemical properties; coagulant activity; antioxidant capacity

\section{Introduction}

Collagen is the most abundant structural protein in the body. Until now, 26 types of collagen have been classified, and they are divided into eight families depending on their structure, chain bonding, and position in the body [1]. Collagen type I is a major form of collagen in higher vertebrates. It is distributed mainly in the skin, muscle, bone, and viscera. Lower vertebrates like fish also have type I collagen that is mostly seen in the scale, skin, bone, and swim bladders [2]. Collagen molecules possess distinctive properties such as biodegradation, weak antigen expression, biocompatibility, and self-assembling fibril formation [3]. Due to its versatility, collagen has been widely used in the food, cosmetic, and healthcare industries. Recently, some researchers have demonstrated that collagen 
can be used as a novel protein-based material in biomedical applications [4-7]. Collagen has been used alone [8] or in combination with other biopolymers such as chitosan and alginate to produce degradable scaffolds for diabetic wound healing [7] and skin tissue engineering $[4-6,9,10]$. However, collagen having a high molecular weight (MW) shows lower bioactivities than collagen peptides that have low MW [11]. Besides, individual biopolymers do not possess desired properties such as biodegradation and mechanical toughness. Fortunately, cross-linked biopolymers could possess such properties [12].

Alginate is a heteropolysaccharide that consists of two-unit monosaccharides: Dmannuronic acid (M) and L-guluronic acid $(\mathrm{G})$ [13]. This biopolymer has been widely used in a variety of industries such as food, cosmetics, and healthcare. Due to the physicochemical properties of alginate, which change according to its MW, alginate is depolymerized using hydrogen peroxide [14] and periodate [15]. According to Li et al. (2009), the depolymerized alginate can be used in biodegradable tissue engineering and drug delivery because it shows a faster degradation rate compared with that of unmodified alginate [14]. However, the depolymerization process of alginate uses many highly concentrated chemicals that might result in some risks to human health [16]. Fortunately, alginate was also depolymerized using subcritical water at $180{ }^{\circ} \mathrm{C}-250{ }^{\circ} \mathrm{C}$ [13]. Subcritical water is water at a temperature above $100{ }^{\circ} \mathrm{C}$ and below $374{ }^{\circ} \mathrm{C}$ and pressure high enough to keep it in a liquid state [17]. Under subcritical water conditions, the depolymerization sequence undoubtedly occurs and could allow the modification of alginate MW distributions [13]. There has been one study about the influences of different MW of oxidized alginate using sodium periodate cross-linked with collagen fiber [15]. However, the effects of low MW of both collagen and alginate on the properties of collagen-based scaffolds have not been examined.

Most of the distinctive properties in extracted collagen are lost or weaker than those in its natural state due to the influences of extraction processes. The loss of the original characters of collagen causes significant restraint in its biotechnological applications [3]. To overcome these problems, cross-linking treatment is necessary to link collagen molecules or collagen with other biopolymers in collagen-based biomaterials. Chemical methods and physical methods are two types of cross-linking methods recently used to improve the properties of collagen-based scaffolds [9]. In chemical methods, some cross-linkers have been commonly used to enhance the physical properties of collagen-based biomaterials such as 1-ethyl-3-(3-dimethylaminopropyl) carbodiimide/N-hydroxysuccinimide (EDC/NHS) [5,18], glutaraldehyde (GTA) [9,19], and genipin [20]. Among cross-linking agents, glutaraldehyde is inexpensive and predominantly employed since it can react with functional groups in both proteins and carbohydrates and can provide materials with substantial improvement in tensile properties [21]. Moreover, it is reported that GTA is noncytotoxic at a concentration of up to $8 \%$ [21,22].

From the literature review, in the present work, we used collagen (6000 and 25,000 Da) and alginate unmodified and modified by subcritical water at 110,120 , and $130{ }^{\circ} \mathrm{C}$ for producing composite scaffolds with a hypothesis that they could be highly flexible and bioactive but still could maintain distinctive properties of biodegradable scaffolds. The water-soluble scaffolds were cross-linked by GTA in an aqueous ethanol solution. Finally, the scaffolds were characterized in terms of Fourier-transform infrared spectroscopy (FTIR), microstructure (SEM), porosity, weight loss, water retention, mechanical properties, enzymatic degradation, antioxidant activity, and in vitro blood coagulant capacity.

\section{Results}

\subsection{Molecular Weight of Collagen and Alginate}

MW of collagen and subcritical water modified sodium alginate were determined using gel permeation chromatography (GPC) and the results were presented in Table 1. MW of original alginate ranged from 32,000 to 250,000 Da, and its MW decreased to 125,000 , 63,000 , and $21,000 \mathrm{Da}$, as the thermal treatment process increased from $110^{\circ} \mathrm{C}, 120^{\circ} \mathrm{C}$, and $130{ }^{\circ} \mathrm{C}$, respectively. 
Table 1. Molecular weights of collagen and alginate.

\begin{tabular}{ccc}
\hline Materials & Average Molecular Weight (Da) & Abbreviation \\
\hline Collagen 1 & $\sim 6000$ & $\mathrm{C} 6$ \\
Collagen 2 & 25,000 & $\mathrm{C} 25$ \\
\hline Untreated alginate & $32,000-250,000$ & $\mathrm{~A} 250$ \\
Alginate hydrolyzed at $110^{\circ} \mathrm{C}$ & 125,000 & $\mathrm{~A} 125$ \\
Alginate hydrolyzed at $120^{\circ} \mathrm{C}$ & 63,000 & $\mathrm{~A} 63$ \\
Alginate hydrolyzed at $130^{\circ} \mathrm{C}$ & 21,000 & A21 \\
\hline
\end{tabular}

\subsection{Degree of Cross-Linking}

Cross-linking degree is related to free amine groups and they are inversely proportional. Glutaraldehyde (GTA) can cross-link collagen molecules via the reaction between free amine groups of lysine and hydroxyl-lysine amino acid residues of the polypeptide chains with the aldehyde groups [19] and can react with functional groups in both proteins and carbohydrates [21]. The cross-linking degree of scaffolds that are made from collagen (6000 and 25,000 Da) and alginate with and without hydrothermal treatment was determined and presented in Figure 1. The results showed that there was a comparison in cross-linking degree of scaffolds including C6-A250, C25-A250, C25-A125, and C25-A63 with approximately $58 \%$. However, sponge C25-A21 showed a slight decrease although the difference was not statistically significant.

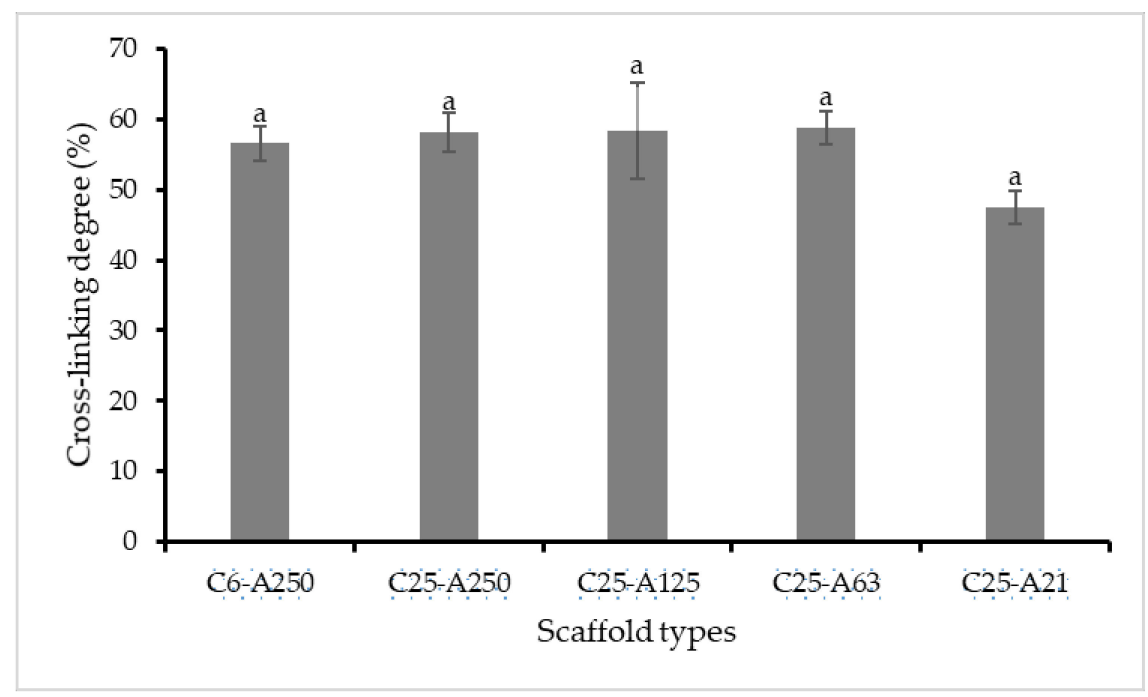

Figure 1. Cross-linking degree of collagen-alginate scaffolds. C6-A250—scaffold contains collagen (6000 Da) and alginate (32,000-250,000 Da); C25-A250—scaffold contains collagen (25,000 Da) and alginate (32,000-250,000 Da); C25-A125—scaffold contains collagen (25,000 Da) and alginate (125,000 Da); C25-A63—scaffold contains collagen (25,000 Da) and alginate (63,000 Da); C25-A21—scaffold contains collagen (25,000 Da) and alginate (21,000 Da). Letters "a" indicate that cross-linking degree of the scaffolds are not significantly different $(p \leq 0.05)$.

\subsection{FTIR Analysis}

Fourier-transform infrared spectroscopy (FTIR) spectra and specific wavelengths of functional groups of pure collagen, alginate, and scaffolds (Figure 2 and Table 2) confirmed the homogeneity and changes in the chemical structure of sponges. For alginate, bands at wavelengths approximately 1600 and $1404 \mathrm{~cm}^{-1}$ are related to asymmetric and symmetric stretching vibration peaks of carboxylate salt groups, whereas a band at $1022 \mathrm{~cm}^{-1}$ is typically for the C-O-C stretching of glycosidic bonds $[5,23]$. In the spectra of collagen, there are five characteristic bands including amide A, amide B, amide I, amide II, and amide III. Specifically, the peak at wavelength $3282 \mathrm{~cm}^{-1}$ is typically for $\mathrm{N}-\mathrm{H}$ stretching vibrations 
representing amide A. The next band at approximately $3057 \mathrm{~cm}^{-1}$ is typically for $\mathrm{C}-\mathrm{H}$ stretching of amide $\mathrm{B}$, whereas the band at $1627 \mathrm{~cm}^{-1}$ is characteristic for the stretching vibrations of $\mathrm{C}=\mathrm{O}$ couples to $\mathrm{N}-\mathrm{H}$ of amide $\mathrm{I}$. The band at $1525 \mathrm{~cm}^{-1}$ is represented for stretching vibrations of $\mathrm{N}-\mathrm{H}$ couple to C-N of amide II. A typical band of amide III is also observed at wavelength approximately $1236 \mathrm{~cm}^{-1}$. The FTIR peaks of scaffolds are the combination of collagen and alginate peaks that showed all amide bands of collagen and glycosidic bonds C-O-C of alginate, indicating that composite scaffolds were successfully fabricated.

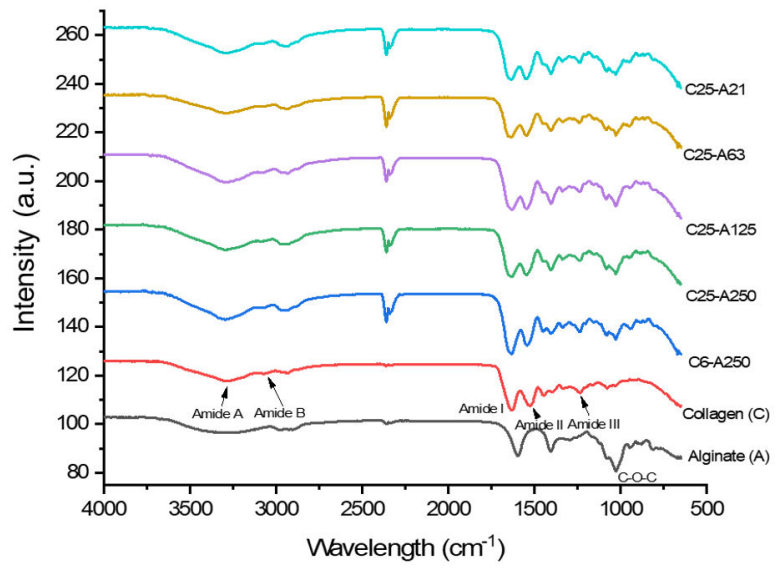

Figure 2. FTIR spectra of pure materials and scaffolds. C6-A250—scaffold contains collagen (6000 Da) and alginate (32,000-250,000 Da); C25-A250 - scaffold contains collagen (25,000 Da) and alginate (32,000-250,000 Da); C25-A125—scaffold contains collagen (25,000 Da) and alginate (125,000 Da); C25-A63-scaffold contains collagen (25,000 Da) and alginate (63,000 Da); C25-A21—scaffold contains collagen $(25,000 \mathrm{Da})$ and alginate $(21,000 \mathrm{Da})$.

Table 2. Peak positions of FTIR spectra of pure materials and scaffolds ("-"- - not applicable).

\begin{tabular}{ccccccc}
\hline \multirow{2}{*}{$\begin{array}{c}\text { Type of } \\
\text { Fabrication }\end{array}$} & \multicolumn{6}{c}{ Absorption Band Peaks (cm $\left.\mathbf{( c}^{-\mathbf{1}}\right)$} \\
\cline { 2 - 7 } & Amide A & Amide B & Amide I & Amide II & Amide III & C-O-C \\
\hline Collagen & 3282 & 3057 & 1627 & 1525 & 1236 & - \\
Sodium alginate & - & - & - & - & - & 1024 \\
C6-A250 & 3301 & 3074 & 1635 & 1542 & 1240 & 1028 \\
C25-A250 & 3301 & 3095 & 1638 & 1540 & 1240 & 1024 \\
C25-A125 & 3295 & 3082 & 1633 & 1540 & 1239 & 1029 \\
C25-A63 & 3301 & 3071 & 1636 & 1540 & 1237 & 1026 \\
C25-A21 & 3289 & 3068 & 1639 & 1546 & 1237 & 1027 \\
\hline
\end{tabular}

\subsection{Microstructure Analysis (SEM) of the Scaffolds}

The porous structure of scaffolds plays a crucial role that can have a significant impact on other properties such as cell attachment, proliferation, neovascularization, and diffusion of oxygen and necessary nutrients during the healing process. Hence, ideal scaffolds that can be applied in tissue engineering should have a mean pore size between 100 and $200 \mu \mathrm{m}$ [5]. Therefore, in this study, cross-section images of the scaffolds were investigated by scanning electron microscope (SEM) to confirm their porous organization, and the results are presented in Figure 3. Cross-section images showed that the pore size of scaffolds is less than $500 \mu \mathrm{m}$, and there were some differences between them. C6-A250 exhibited ununiform and less interconnected porous architecture, whereas the remaining scaffolds were quite uniform and well interconnected. C25-A125 has the largest pores; C25-A63 had a smaller pore size (100-200 $\mu \mathrm{m})$ and relatively round shape, whereas pores of C25-A250 and C25-A21 scaffolds had long, narrow shape and were less interconnected as compared with those of C25-A125 and C25-A63 scaffolds. 


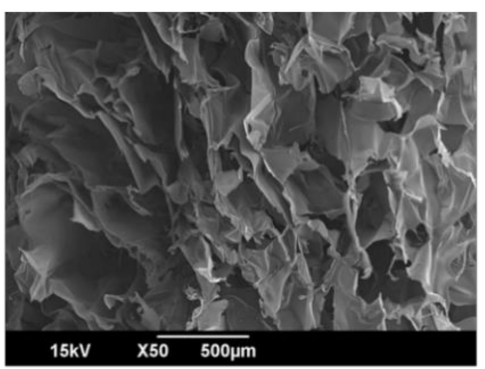

C6-A250

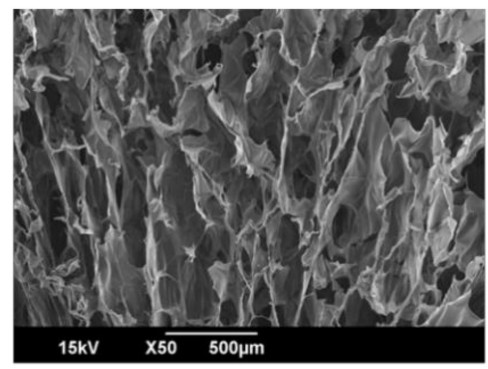

C25-A250



C25-A125

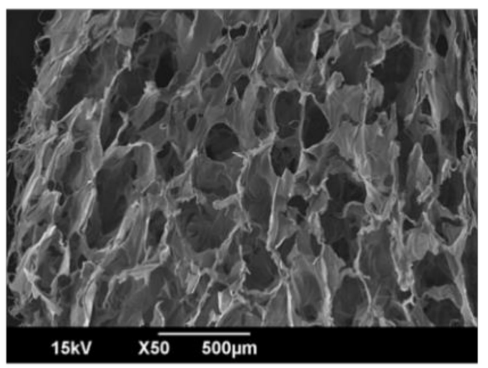

C25-A63

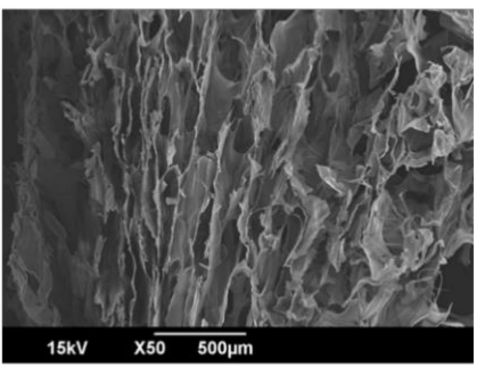

C25-A21

Figure 3. Scanning electron microscope of pure materials and scaffolds. C6-A250—scaffold contains collagen (6000 Da) and alginate (32,000-250,000 Da); C25-A250-scaffold contains collagen (25,000 Da) and alginate (32,000-250,000 Da); C25-A125-scaffold contains collagen (25,000 Da) and alginate (125,000 Da); C25-A63—scaffold contains collagen (25,000 Da) and alginate (63,000 Da); C25-A21—scaffold contains collagen (25,000 Da) and alginate (21,000 Da).

\subsection{Porosity, Density, and Compressive Properties of the Scaffolds}

Porosity is also one of the important parameters of scaffolds that are applied in tissue engineering and should be greater than $90 \%$ [5]. In this study, the porosity of all scaffolds (Figure 4) was approximately 93\%, and there was no significant difference between them. In addition, their density was not statistically different and ranged from 0.44 to $0.56 \mathrm{mg} / \mathrm{mm}^{3}$.

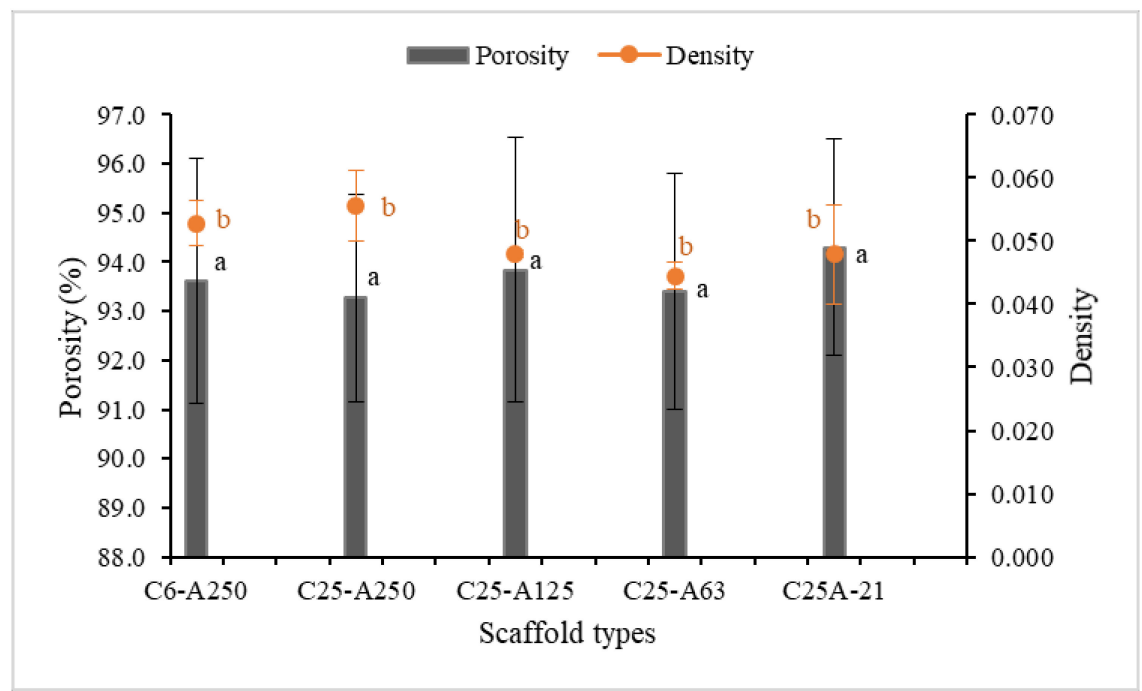

Figure 4. Porosity and density of scaffolds. C6-A250 - scaffold contains collagen (6000 Da) and alginate (32,000-250,000 Da); C25-A250-scaffold contains collagen (25,000 Da) and alginate (32,000-250,000 Da); C25-A125-scaffold contains collagen (25,000 Da) and alginate (125,000 Da); C25-A63—scaffold contains collagen (25,000 Da) and alginate (63,000 Da); C25-A21scaffold contains collagen $(25,000 \mathrm{Da})$ and alginate $(21,000 \mathrm{Da})$. Letters "a" indicate that the porosity of all the scaffolds are not significantly different $(p \leq 0.05)$; letters " $\mathrm{b}$ " indicate that the density of all scaffolds are not significantly different $(p \leq 0.05)$. 


\subsection{Tensile and Compressive Properties}

The tensile and stress-strain curves of the composite scaffolds are presented in Figure 5. The tensile (Figure 5A) showed that the C6-A250 scaffold had the lowest tensile strength with approximately $0.04 \mathrm{MPa}$. The hardness of C25-A125 and C25-A63 was significantly higher than that of the C25-A21 scaffold. For compressive property, all scaffolds are highly flexible, and they are comparable with the results from a previous study [24]. C6A250 and C25-A250 scaffolds were the most flexible ones, whereas the remaining scaffolds showed a lower level of flexibility.

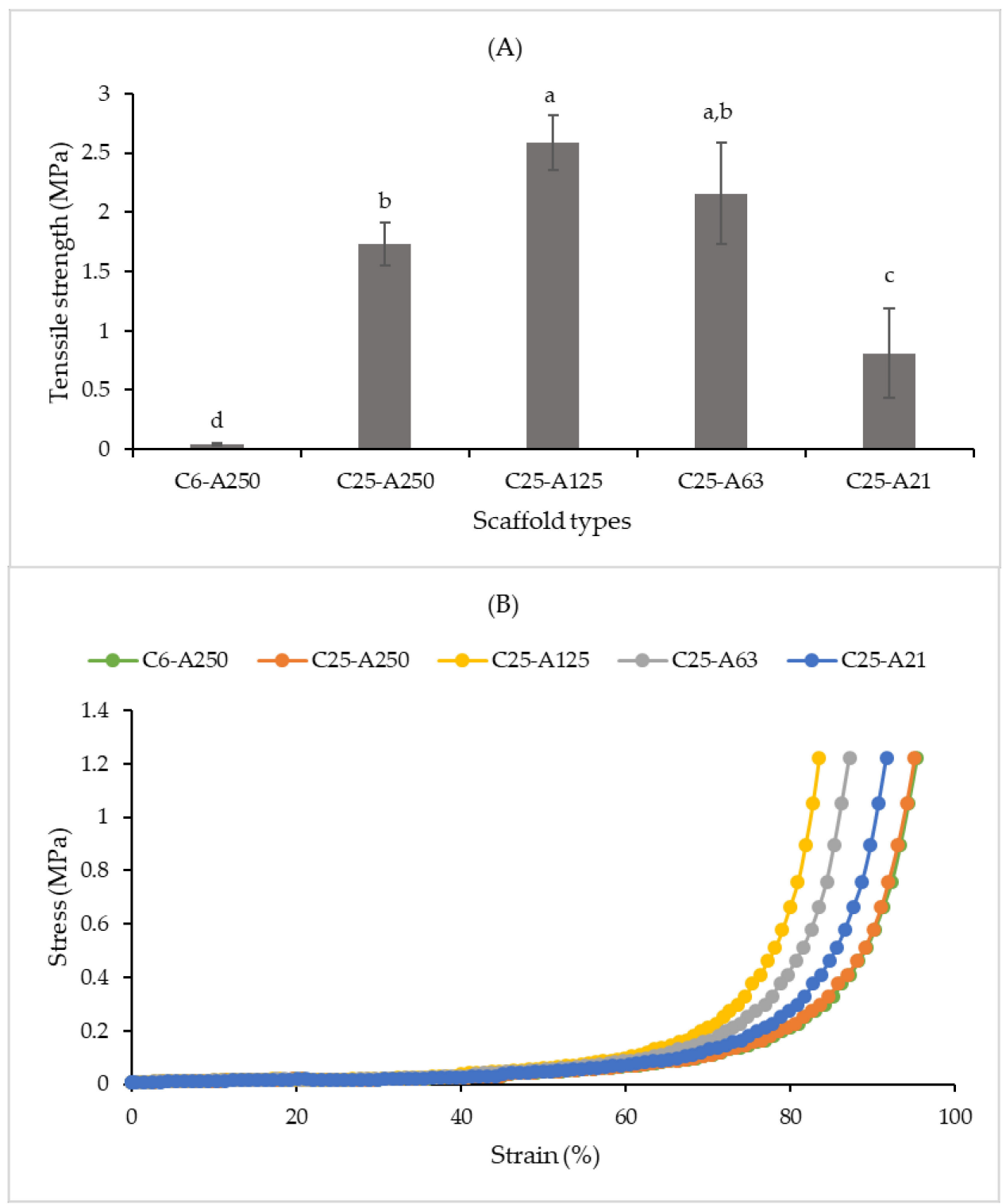

Figure 5. Tensile strength (A) and compressive property (B). C6-A250—scaffold contains collagen (6000 Da) and alginate (32,000-250,000 Da); C25-A250—scaffold contains collagen (25,000 Da) and alginate (32,000-250,000 Da); C25-A125-scaffold contains collagen (25,000 Da) and alginate (125,000 Da); C25-A63—scaffold contains collagen (25,000 Da) and alginate (63,000 Da); C25-A21—scaffold contains collagen (25,000 Da) and alginate (21,000 Da). Different letters (a-d) in (A) indicate that there are significant differences between scaffolds $(p \leq 0.05)$. 


\subsection{Weight Loss and Water Retention Capacity}

Weight loss and water retention properties of composite scaffolds are presented in Figure 6. C6-A250 scaffold had the highest weight loss ratio (Figure 6A) with $35 \%$ after the first day and $70 \%$ after nine days in phosphate buffer at $37^{\circ} \mathrm{C}$. On the other hand, the remaining scaffolds were more stable under the same conditions when their weight loss was less than $10 \%$ after one day incubation and less than $30 \%$ after nine days. The water retention capacity of scaffolds (Figure 6B) was quite high and ranged from 1200\% to $2000 \%$. Among those, C6-A250 has the lowest water retention with approximately $1240 \%$, and it was significantly different from the C25-A63 scaffold. On the other hand, C25-A63 had the highest water retention capacity with approximately $2157 \%$. Although the difference between C25-A250, C25-A125, C25-A63, and C25-A21 was not statistically significant, there was a trend that the water retention capacity of scaffolds got a peak at C25-A63 (Figure 6B).

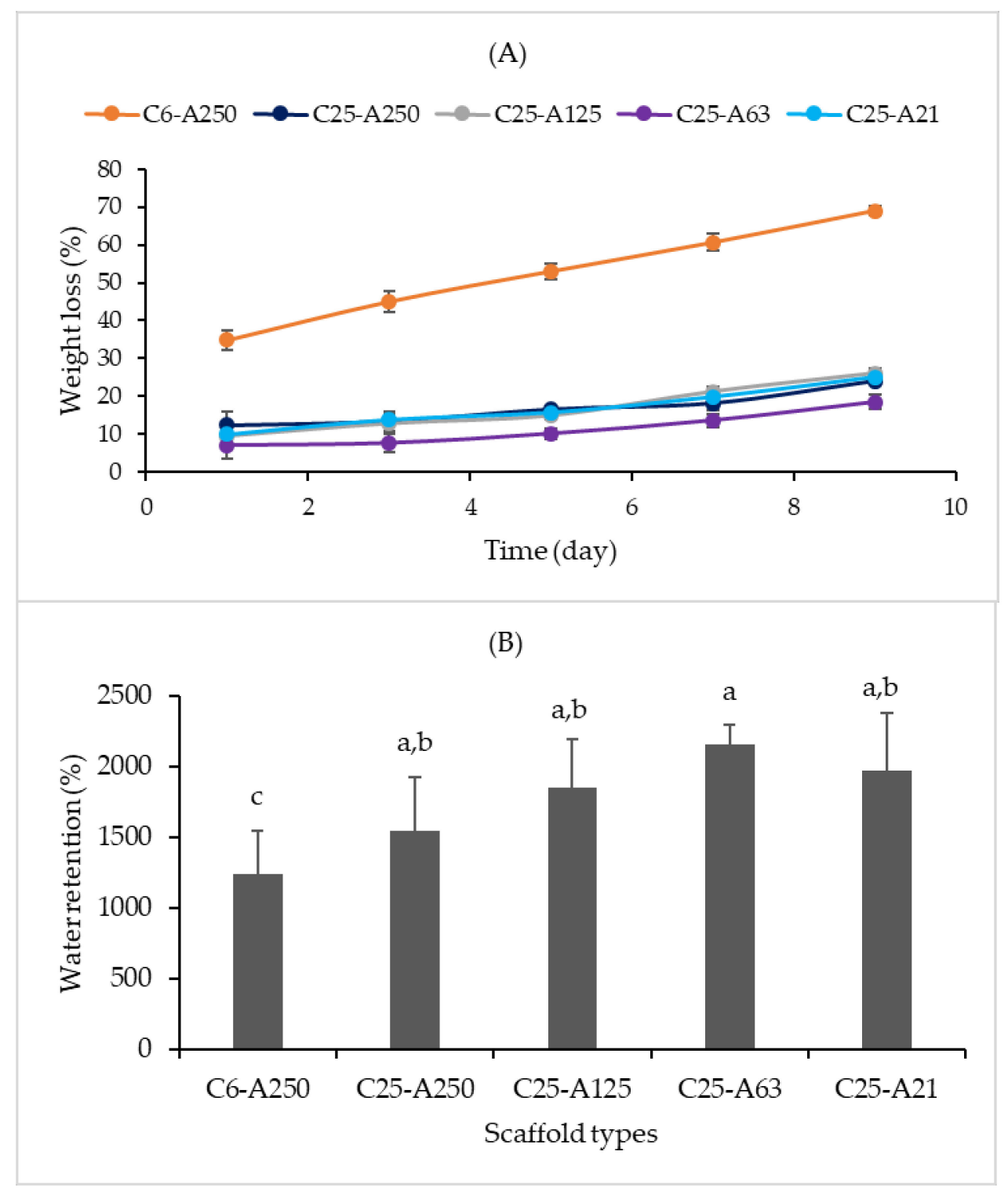

Figure 6. Weight loss and water retention capacity of scaffolds. (A) - Weight loss; (B) - Water retention capacity. C6-A250scaffold contains collagen (6000 Da) and alginate (32,000-250,000 Da); C25-A250—scaffold contains collagen (25,000 Da) and alginate (32,000-250,000 Da); C25-A125-scaffold contains collagen (25,000 Da) and alginate (125,000 Da); C25-A63scaffold contains collagen (25,000 Da) and alginate (63,000 Da); C25-A21—scaffold contains collagen (25,000 Da) and alginate $(21,000 \mathrm{Da})$. Different letters $(\mathrm{a}-\mathrm{c})$ in $(\mathrm{B})$ indicate that there are significant differences between scaffolds $(p \leq 0.05)$. 


\subsection{Enzymatic Degradation}

Enzymatic degradation of scaffolds in PB pH 7.4 containing collagenase $(60 \mu \mathrm{g} / \mathrm{mL})$ for 5 days was carried out at $37^{\circ} \mathrm{C}$, and the results were presented in Figure 7. The C6-A250 scaffold was fully degraded after incubating $2 \mathrm{~h}$ in collagenase solution. As compared with C6-A250, C25-A250 was more resisted against collagenase when its degradation ratio was approximately $20 \%$ after $2 \mathrm{~h}$ and remained after $72 \mathrm{~h}$ before completely degraded after $96 \mathrm{~h}$. The remaining scaffolds including C25-A125, C25-A63, and C25-A21 were quite stable after incubating for $120 \mathrm{~h}$. In detail, the degradation ratio of these three scaffolds was around $10 \%$ after $2 \mathrm{~h}$ of incubation, and the ratio was less than $30 \%$ after $6 \mathrm{~h}$. More than $50 \%$ of scaffolds was degraded after $24 \mathrm{~h}$ in scaffolds C25-A125 and C25-A21; however, the ratio in C25-A63 was only 45\%. Overall, C25-A63 was more stable than other scaffolds in the enzymatic degradation process.

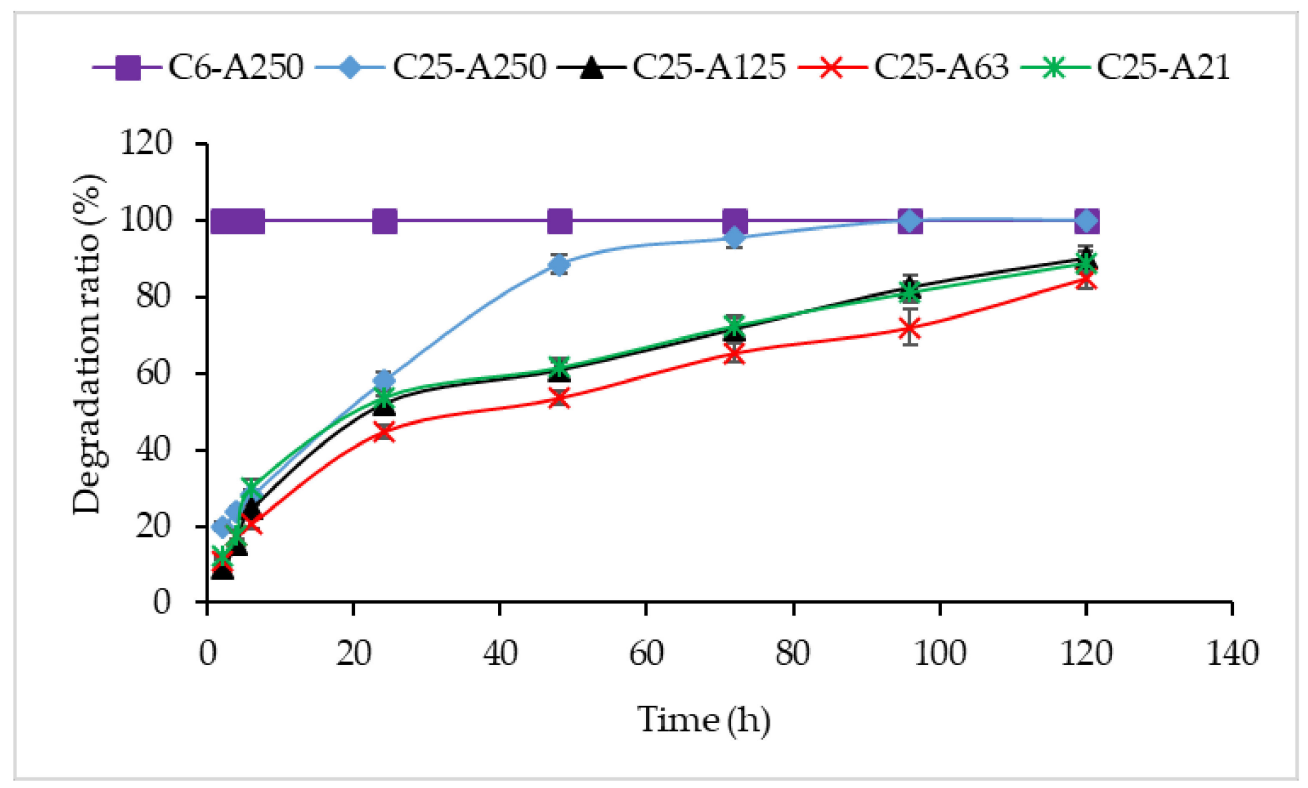

Figure 7. Enzymatic degradation of scaffolds. C6-A250—scaffold contains collagen (6000 Da) and alginate (32,000250,000 Da); C25-A250—scaffold contains collagen (25,000 Da) and alginate (32,000-250,000 Da); C25-A125-scaffold contains collagen $(25,000 \mathrm{Da})$ and alginate (125,000 Da); C25-A63—scaffold contains collagen (25,000 Da) and alginate (63,000 Da); C25-A21—scaffold contains collagen (25,000 Da) and alginate (21,000 Da).

\subsection{Antioxidant Capacity}

The antioxidant capacity of uncross-linked scaffolds (Figure 8) was investigated using two common assays, including $\mathrm{ABTS}^{+}(\mathrm{A})$ and $\mathrm{DPPH}(\mathrm{B})$ radical scavenging. There was no significant difference in scavenging capacity between scaffolds. However, there was a trend that C6-A250 scaffolds have the highest percentage scavenging with approximately $23 \%$ and $11 \%$ for $\mathrm{ABTS}^{+}$and $\mathrm{DPPH}$, respectively. Among the remaining scaffolds, there was another trend that radical scavenging activity of scaffolds tended to increase with the decrease in MW of alginate or the increase in temperature that was used to depolymerize alginate polymers. DPPH percentage scavenging of C25-A250, C25-A125, C25-A63, and C25-A21 was $8.6 \% \pm 0.4 \%, 8.8 \% \pm 0.2 \%, 9.0 \% \pm 0.5 \%$, and $9.5 \% \pm 0.4 \%$, respectively, and $\mathrm{ABTS}^{+}$percentage scavenging of these samples was $20.6 \pm 0.5,22.0 \pm 0.2,22.6 \pm 0.9$, and $23.0 \pm 1.4$, respectively. 
(A)

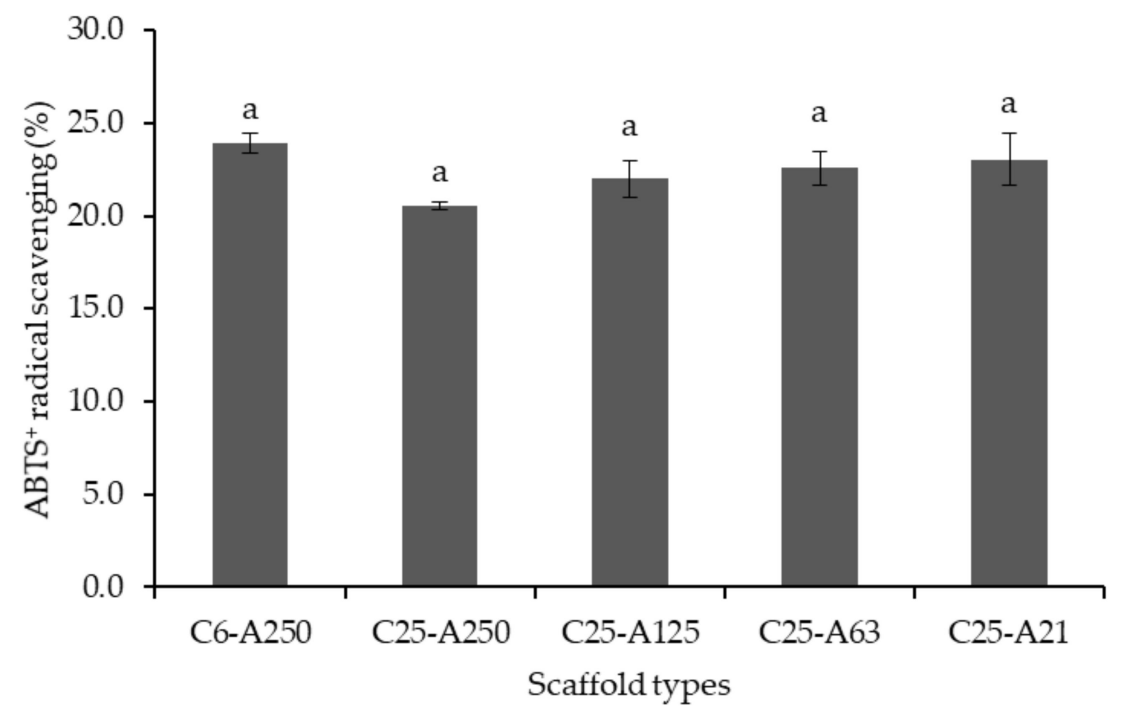

(B)

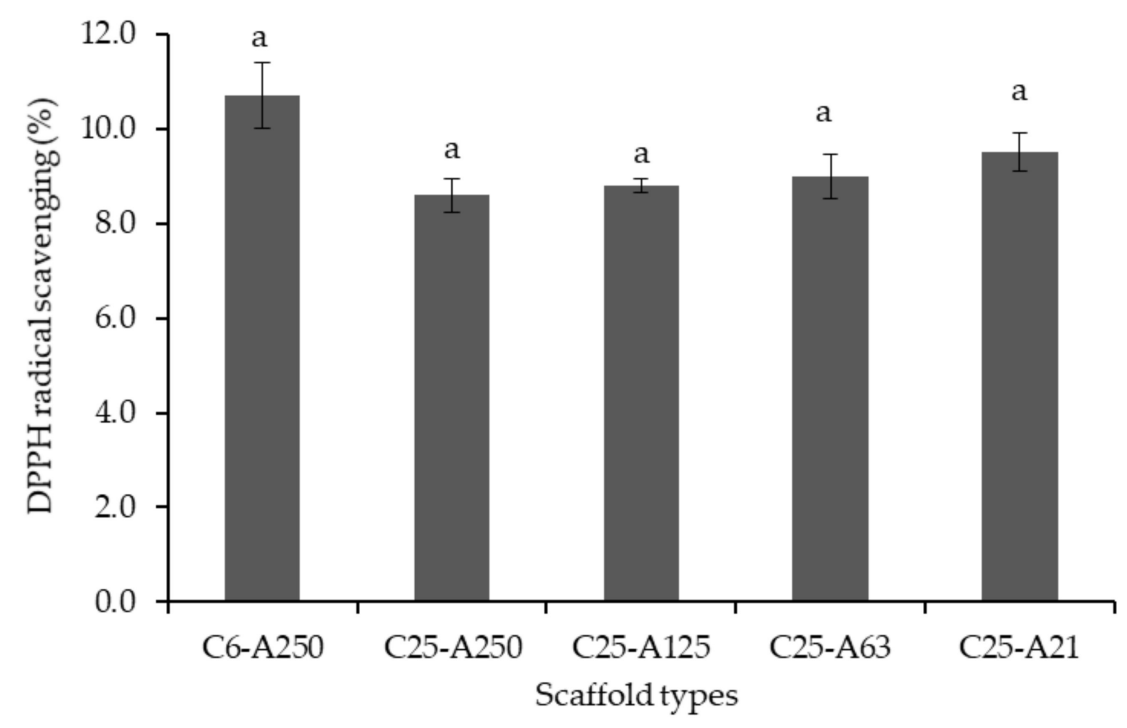

Figure 8. Antioxidant capacity of collagen-alginate scaffolds: (A)- $\mathrm{ABTS}^{+}$radical scavenging and (B)-DPPH radical scavenging. C6-A250—scaffold contains collagen (6000 Da) and alginate (32,000-250,000 Da); C25-A250-scaffold contains collagen (25,000 Da) and alginate (32,000-250,000 Da); C25-A125-scaffold contains collagen (25,000 Da) and alginate (125,000 Da); C25-A63-scaffold contains collagen (25,000 Da) and alginate (63,000 Da); C25-A21-scaffold contains collagen $(25,000 \mathrm{Da})$ and alginate $(21,000 \mathrm{Da})$. Letters " $a$ " indicate that there is no significant difference between scaffolds $(p \leq 0.05)$.

\subsection{In Vivo Blood Coagulant Assay}

In vitro blood coagulation activity of collagen-alginate against human plasma of scaffolds was examined, and the result is presented in Figure 9. In this test, deionized water was used as the control test to determine the clotting time of human plasma. The time for plasma clot form of the control was recorded with approximately $180 \pm 8.4 \mathrm{~s}$ and was similar to that of C25-A250 (178 $\pm 7.3 \mathrm{~s}$ ). For the C6-A250 scaffold, the clotting time $(169 \pm 9.2 \mathrm{~s})$ was reduced $11 \mathrm{~s}$ as compared with the control and $9 \mathrm{~s}$ shorter than C25-A250 scaffolds. The remaining scaffolds that contained modified alginate tended to improve the coagulant activity and increased with the increase in the treating temperature of subcritical 
water from $110^{\circ} \mathrm{C}$ to $130^{\circ} \mathrm{C}$. The scaffolds $\mathrm{C} 25-\mathrm{A} 125$ reduced the blood clotting time by $6 \mathrm{~s}$ as compared with the control one. Especially, scaffolds C25-A63 and C25-A21 significantly reduced the clotting time ( $33 \pm 8.6 \mathrm{~s}$ and $37 \pm 8.1 \mathrm{~s})$, respectively, in comparison with the control.

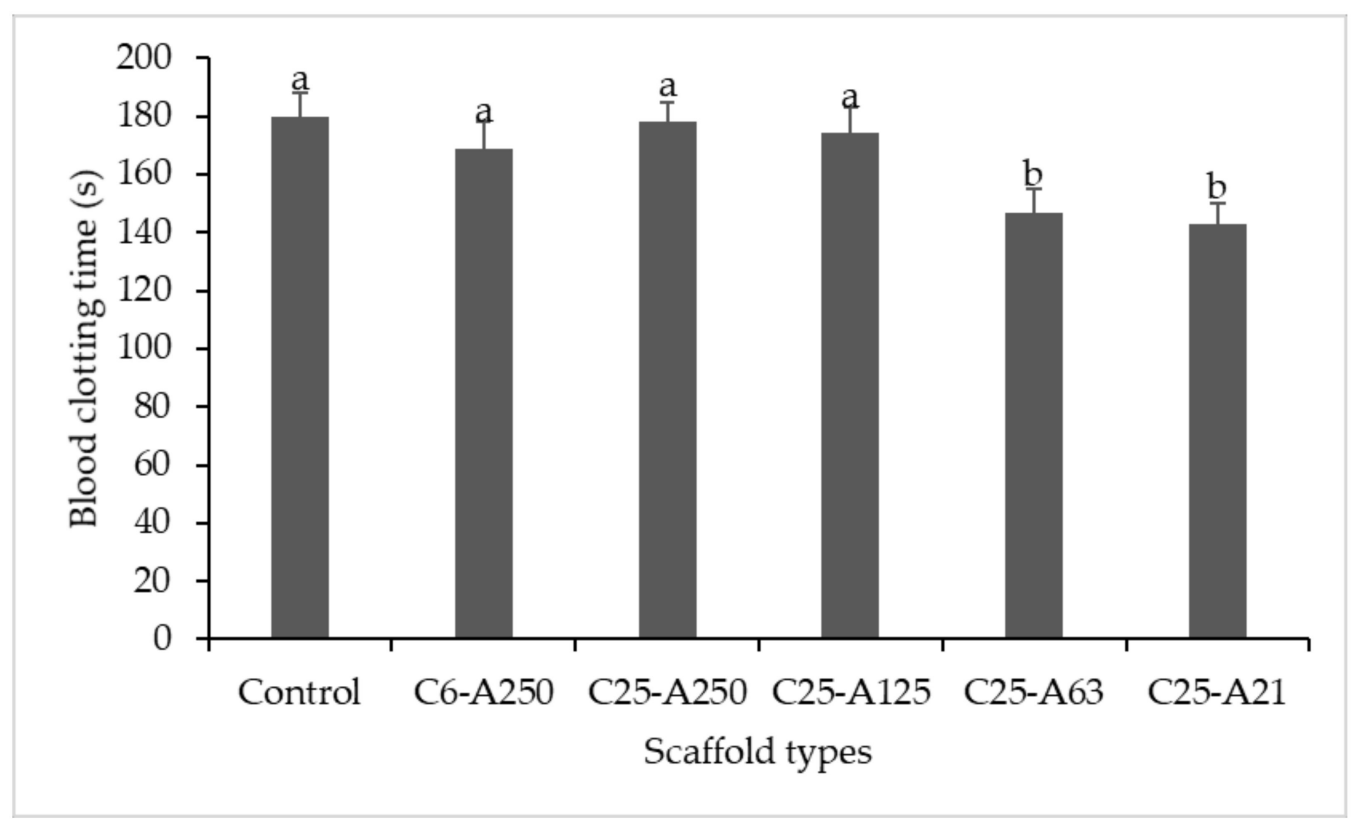

Figure 9. Blood coagulant activity of sponges. C6-A250-scaffold contains collagen (6000 Da) and alginate (32,000250,000 Da); C25-A250—scaffold contains collagen (25,000 Da) and alginate (32,000-250,000 Da); C25-A125-scaffold contains collagen (25,000 Da) and alginate (125,000 Da); C25-A63—scaffold contains collagen (25,000 Da) and alginate (63,000 Da); C25-A21—scaffold contains collagen (25,000 Da) and alginate (21,000 Da). Different letters (a-b) indicate that there are significant differences between scaffolds $(p \leq 0.05)$.

\section{Discussion}

In this study, we hypothesized that scaffolds made from the low MW of collagen as well as alginate might have a soft structure and perform good functionalities. However, they remain distinctive properties that can be suitable in wound-stressing applications. One of those is flexibility property that is beneficial for wound stressing since it can have close contact with the wounded surface [24]. For that reason, two different MWs of collagen (6000 Da and 25,000 Da) were employed. Besides, MW of alginate was modified using subcritical water at temperatures $110^{\circ} \mathrm{C}, 120^{\circ} \mathrm{C}$, and $130{ }^{\circ} \mathrm{C}$. This is the first study on the use of subcritical water modified alginate that was then applied in tissue engineering. According to Aida et al. (2010), hydrothermal treatments are a promising method in the modification of the structure of alginate molecules. Under hydrothermal conditions, alginate is decomposed at the glycosidic bonds through an acid hydrolysis pathway [13]. When the temperature increased from $110{ }^{\circ} \mathrm{C}$ to $130{ }^{\circ} \mathrm{C}$, the molecular weight of alginate decreased from $125,000 \mathrm{Da}$ to $21,000 \mathrm{Da}$, whereas the original alginate has $\mathrm{MW}$ at around between 32,000 and 250,000 Da.

Scaffolds fabricated by low MW collagen and alginate are water-soluble; therefore, they need to be cross-linked to make them more stable in aqueous conditions. In our work, some screening experiments about the use of cross-linking agents including EDC, formaldehyde, and GTA in 95\% ethanol were carefully carried out. The results showed that formaldehyde and GTA had better cross-linking ability than EDC; however, formaldehyde is known as more toxic than GTA. Therefore, in this study, we developed a simple technique to cross-link water-soluble collagen-based biomaterials using GTA in 95\% ethanol. Results indicated that the cross-linking degree was found to be between $48 \%$ and $60 \%$. This result 
was similar to that reported in a previous study when tilapia skin collagen sponge has approximately $60 \%$ after cross-linking by $0.625 \%$ GTA [25]. According to Choi et al. (1999), gelatin and alginate could be cross-linked via carboxyl groups that are rich in these two polymers when EDC is used as a cross-linker [26]. Between collagen and other proteins, GTA reacts with the free amine group of lysine or hydroxyl-lysine amino acid residues of the polypeptide chains to form Schiff base intermediates [19]. Cross-linking degree tended to decrease when collagen combined with alginate modified at $130{ }^{\circ} \mathrm{C}$. This might be due to more alginate molecules that are produced under subcritical water hydrolysis cross-linked with GTA via their -OH groups. Therefore, there was an increase in the number of GTA molecules cross-linked with alginate, leading to the decrease in the number of GTA molecules cross-linked with collagen. In this case, the degree of cross-link between alginate with GTA cannot be tested by TNBS method. Fortunately, cross-linked alginate could also cross-link with collagen. Consequently, although the degree of crosslink between collagen and GTA slightly decrease (Figure 1), the total cross-linking degree might not be much different. As we expected, low MW of collagen and alginate fabricated scaffolds cross-linked with GTA possess a flexible structure. According to L. Sun et al. (2018), GTA can cross-link collagen molecules via covalent bonds between its carbonyl groups by removing two oxygen atoms and amine groups of collagen [25]. However, intramolecular forces between collagen molecules may be weaker than intermolecular forces inside them. This might be the reason that the C6-A250 scaffold possessed a soft structure than those obtained from collagen 25,000 Da. SEM image of C6-A250 (Figure 3) also confirmed this phenomenon when its porous structure had some physical damages that are not found in the remaining scaffolds. Due to the weakness in its structure, the damages to the scaffold might be caused either by themselves or by the sample preparation step for SEM analysis.

In our study, the porosity of scaffolds was determined at approximately $93 \%$. This value was found to be around $90 \%$ in previous work that also studied similar materials [5]. Considering that, the MW of the biopolymers are higher than those used in the present study. Meanwhile, according to some studies, the porosity of high MW collagen alone scaffolds is reported to be around $97 \%$ [8,25]. Therefore, it can be concluded that: first, low MW collagen-based scaffolds might have higher porosity than high MW collagen-based scaffolds; second, collagen alone scaffolds might have higher porosity than collagen-based biomaterials.

Water retention capacity can be influenced by the porous structure of scaffolds. The results from this study demonstrated that C25-A63 scaffolds that had round, small, and interconnected porous structure held the highest water retention ratio, whereas the water retention ratio of scaffolds with a large pore size (C25-A110) or less interconnected (C25A250 and C25-A21) tended to decrease.

Weight loss and enzymatic degradation ratio are also two crucial properties that are significantly affected by the MW of collagen used. Although cross-linking degree in all scaffolds was similar, the high weight loss ratio of C6-A250 as compared with C25-A250 might be caused by its low MW. According to a previous report, low MW collagen is more soluble in aqueous conditions due to the exposure of polar amino acid residues capable of binding water through hydrogen bonds [27]. Consequently, the aqueous solution containing collagenase can quickly accelerate the decomposition of low MW collagen. There are some ways for collagenase to cleavage collagen molecules: First, unwound collagen $\alpha$ chains, but not triple-helical structure, may be a prerequisite for collagenase to cleave interstitial collagen, and second, collagenase could cleave single $\alpha$ chain during collagenolysis [28]. The resistance against collagenase degradation of scaffolds C25-As might be due to the consistency of high MW collagen, which has less unwound $\alpha$ chains and less exposed polar amino acid. Besides, alginate MW could affect the stability of composite scaffolds against enzymatic degradation. Moderate MW of alginate had better protection for the collagen biodegradation process since they might well cover the surface of collagen structure than unmodified alginate and low MW one. 
Although there was no significant difference in antioxidant activity between composite scaffolds, there was a trend that the C6-A250 scaffold showed the highest $\mathrm{ABTS}^{+}$and DPPH radical scavenging activity as compared with the remaining scaffolds. It can be explained that low MW collagen might contain more electron donors that could scavenge free radicals, leading to the formation of stable products [29]. This result once again confirms that low MW collagen is presumed to have better bioavailability than larger peptides and parent proteins [11]. Another trend is that low MW alginate could also assist in the improvement of the antioxidant capacity. Due to the cleavage of glycosidic bonds under subcritical water hydrolysis, more functional groups such as hydroxyl, carbonyl, and carboxyl groups are produced, leading to an increase in the electron donation process for the stabilization of free radicals [30]. Composite scaffolds also showed capability in the reduction of blood coagulation time. The results in this study were consistent with those of previous reports $[8,25]$. Surprisingly, the scaffolds containing alginate modified at $120^{\circ} \mathrm{C}$ and $130{ }^{\circ} \mathrm{C}$ (C25-A63 and C25-A21) significantly reduced blood clotting time as compared with the control test. This may be due to the synergistic effects of the low MW of both collagen and alginate rather than a single compound. More investigation is needed to confirm the mechanism of this effect. Although the biological properties were determined using uncross-linked scaffolds since they are water-soluble, the cross-linked scaffolds might also possess such promising properties. Therefore, further examinations of the scaffolds on animals should be also considered in future studies.

\section{Materials and Methods}

\subsection{Chemicals}

Collagen (6000 and 25,000 Da) was kindly donated by PL Micromed Co., Ltd. (Gyeongsangnam-do, Korea). Alginate with MW ranging from 32,000 to 250,000 Da was obtained from Duksan Company (Gyeonggi-do, Korea). Glutaraldehyde was purchased from Junsei Chemical Co., Ltd. (Tokyo, Japan). The aPTT reagent and human plasma were purchased from Thermo Fisher Scientific, Pittsburgh, PA, USA. Other chemicals were of analytical grade.

\subsection{Methods}

\subsubsection{Modification of Alginate Molecular Size Using Subcritical Water}

The modification of alginate was done using a subcritical water hydrolysis system equipped with a $1 \mathrm{~L}$ reactor. Alginate (3\%) was well suspended in distilled water to assist the hydrolysis before introducing into the reactor. $\mathrm{CO}_{2}$ was used to pressurize the system and to maintain the pressure at 30 bar during the process. Alginate was modified at three different temperatures $\left(110^{\circ} \mathrm{C}, 120^{\circ} \mathrm{C}\right.$, and $\left.130{ }^{\circ} \mathrm{C}\right)$ under subcritical water conditions with a fixed reaction time and pressure ( $30 \mathrm{~min}$ and $30 \mathrm{bar}$, respectively). Because the initial alginate solution possesses high viscosity, the stirring speed needs to be high enough to create a well-mixed solution. Therefore, a stirring speed at $700 \mathrm{rpm}$ was set to assist the depolymerization process well homogeneous. Furthermore, the modified alginate solution was stored at $4{ }^{\circ} \mathrm{C}$ for further experiments.

\subsubsection{Gel Permeation Chromatography}

MW of collagen and subcritical water modified alginate were determined using GPC. First, samples were dissolved in deionized water with a concentration of $3 \mathrm{mg} \mathrm{mL}^{-1}$. The solution was then filtered through a $0.45 \mu \mathrm{m}$ pore size Nylon filter and degassed. In the GPC program, the injection volume was kept at $100 \mu \mathrm{L}$, and $0.1 \mathrm{M}$ of $\mathrm{NaNO}_{3}$ was employed

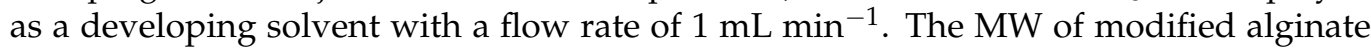
and its distribution were analyzed at $40^{\circ} \mathrm{C}$ using Tosoh EcoSEC HLC-8320 GPC equipped (Tosoh Bioscience, Hesse, Germany) with RI detector and TSKgel guard PW $\times 1+2 \times$ TSKgel MPW $\times 1+$ TSKgel G2500PW $\times 1(7.8 \times 300 \mathrm{~mm})$ column. The determination of the MW of modified alginate and collagen was based on the calibration curve of the pullulan standards (180 to $642 \times 10^{3} \mathrm{~g} \mathrm{~mol}^{-1}$ ) and polyethylene glycol/polyethylene oxide 
standards (600 to 122,000 Da), respectively. The results were analyzed using the EcoSEC software (Tosoh, version No. 1.11, Hesse, Germany).

\subsubsection{Preparation of Collagen-Alginate Scaffolds}

Collagen with different MWs accurately measured and dissolved in $0.02 \mathrm{M}$ acetic acid under stirring heating at $40{ }^{\circ} \mathrm{C}$ to form a solution of $0.8 \%$ of collagen. The solution was then neutralized using $2 \mathrm{M} \mathrm{NaOH}$ in phosphate buffer. Original alginate was dissolved in deionized water under stirring and heating at $45^{\circ} \mathrm{C}$ for $30 \mathrm{~min}$ to get the final concentration of 3\% (similar to the concentration of modified alginate used in Section 4.2.1). Collagen solutions were well mixed with modified and original alginate solutions separately using a stirrer at $250 \mathrm{rpm}$, at room temperature to attain a ratio of collagen/alginate, 7:3 (w/w). The mixtures were then kept at $4{ }^{\circ} \mathrm{C}$ for 2 days under stirring at $130 \mathrm{rpm}$. The resulting mixtures were then centrifuged at $3000 \mathrm{rpm}$ for $15 \mathrm{~min}$ to eliminate accumulated air bubbles before pouring into cell culture plates with a volume of $40 \mathrm{~mL} /$ plate. Next, plates containing collagen-alginate blend were kept at $25^{\circ} \mathrm{C}$ for $12 \mathrm{~h}$ allowing collagen gelation. The incubated blends were subsequently frozen at $-20^{\circ} \mathrm{C}$ and $-80^{\circ} \mathrm{C}$ for $12 \mathrm{~h}$ per each step. The frozen blends were freeze-dried using a freeze dryer HyperCool HC4110 (GYROEN Co., Ltd., Gyeonggi-do, Korea). The lyophilized 3D scaffolds were then cross-linked using $0.5 \%$ GTA in $95 \%$ ethanol for $1.5 \mathrm{~h}$ at room temperature before cleaning with absolute ethanol five times and freeze-dried for $12 \mathrm{~h}$. The cross-linked scaffolds were stored at room temperature in a zip bag for further characterization.

\subsection{Characterizations of Collagen-Alginate Scaffolds}

\subsubsection{Fourier-Transform Infrared Spectroscopy (FTIR)}

Scaffolds were mixed with $\mathrm{KBr}$ (spectrum pure) with a ratio of approximately 1:100, $w / w$. The mixture was ground and pressed into transparent sheets. To determine the functional groups of scaffolds, FTIR spectra were determined at a resolution of $4 \mathrm{~cm}^{-1}$ with wavelength ranging from 400 to $4000 \mathrm{~cm}^{-1}$ at room temperature using Perkin Elmer, Inc. (Waltham, MA, USA), and data were analyzed using Origin 2019b software (OriginLab Corporation, Version 9.65, Northampton, MA, USA).

\subsubsection{Microstructure Characterization}

The microstructure of scaffolds was characterized using a JEOL, JSM-6700 F, Field Emission Scanning Electron Microscopy (JEOL Ltd., Akishima, Tokyo 196-8558, Tokyo, Japan).

\subsubsection{Porosity and Density Assessment}

The measurement of porosity and density of scaffolds was done using an ethanol infiltration method reported previously [31]. Porosity $(P)$ was indirectly measured via volumes $\left(V_{s}\right)$ and pores $\left(V_{p}\right)$ of the scaffolds using the equation $P=V_{p} / V_{s} \times 100 \%$. According to this, $V_{s}$ was determined from the three-dimensional geometry (length, width, and height) of the scaffolds. $V_{p}$ was obtained from the equation $V_{p}=\left(W_{c}-W_{o}\right) / \rho_{e}$, where $\rho_{e}\left(0.789 \mathrm{mg} \mathrm{mL}^{-1}\right)$ is ethanol density at room temperature and $W_{o}$ and $W_{c}$ are initial weight and after weight of the scaffolds, respectively, and they are determined by an ethanol infiltration method. Briefly, the weighed scaffolds $\left(W_{o}\right)$ were incubated in absolute ethanol at room temperature for $15 \mathrm{~min}$ under reduced pressure using a desiccator to remove air bubbles. The scaffolds were taken out and wiped thoroughly using a filter paper to remove ethanol on the surface and then weighed immediately $\left(W_{c}\right)$. The experiment was done in triplicate.

\subsubsection{Weight Loss}

Weight loss of the scaffolds was observed for 9 days with an interval of 2 days. Briefly, precisely weighed scaffolds $\left(W_{o}\right)$ were incubated in $1.5 \mathrm{~mL}$ of phosphate buffer $\mathrm{pH} 7.4$ at $37^{\circ} \mathrm{C}$ in an oven. For every 2 days, incubated scaffolds were taken out, lyophilized, and weighed $\left(W_{t}\right)$. Subsequently, lyophilized scaffolds were again incubated in $1.5 \mathrm{~mL}$ of fresh 
phosphate buffer solution. The weight loss ratio was calculated as presented in formula 1. The experiment was carried in triplicate for each scaffold, and the results are reported as mean \pm standard deviation (SD) $(n=3)$.

$$
W_{L}(\%)=\left[\left(W_{0}-W_{t}\right) / W_{0}\right] \times 100
$$

\subsubsection{Tensile and Compressive Property}

Scaffolds were prepared in $10 \times 10 \times 4 \mathrm{~mm}$ for compressive assessment and $20 \times 5 \times 4$ for the tensile test. The measurements were done by using a universal testing machine LR5K Plus (LLOYD instruments, Hampshire, United Kingdom) at room temperature. The cross-head speed of both tests was set at $0.1 \mathrm{~mm} / \mathrm{s}$. In the tensile test, the experiment was progressed until failure, and in the compressive test, the compressive stress was measured at $90 \%$ strain since the scaffolds did not fracture during the compression. At least five samples per scaffold were used in both tests, and the results were expressed as mean \pm SD $(n=5)$.

\subsubsection{Water Retention Capacity}

To determine the water retention capacity of scaffolds, the weighed scaffolds $\left(W_{0}\right)$ were immersed into PBS ( $\mathrm{pH} 7.4$ ) at $37^{\circ} \mathrm{C}$ for $24 \mathrm{~h}$. Then, swollen scaffolds were taken out, carefully wiped with a tissue paper, and immediately weighed $\left(W_{1}\right)$. Water retention $\left(W_{R}\right)$ was done in triplicate and expressed as percentage (\%):

$$
W_{R}(\%)=\left[\left(W_{1}-W_{0}\right) / W_{0}\right] \times 100
$$

\subsubsection{Degree of Cross-Linking}

The determination of the cross-linking degree in the scaffolds was done according to the method reported in the previous study [8]. Briefly, sponges (5 mg) were mixed with $1 \mathrm{~mL}$ of $4 \% \mathrm{NaHCO}_{3}(w / v)$ for $30 \mathrm{~min}$ at room temperature. Then, the mixture was added with $1 \mathrm{~mL}$ of TNBS $0.5 \%$ before incubating at $40{ }^{\circ} \mathrm{C}$ for $2 \mathrm{~h}$. Subsequently, the reaction was terminated by adding $3 \mathrm{~mL}$ of $6 \mathrm{M} \mathrm{HCl}$ and was then incubated at $60^{\circ} \mathrm{C}$ for $90 \mathrm{~min}$ to terminate the reaction. After incubation, the mixture was diluted with $5 \mathrm{~mL}$ distilled water and cooled to room temperature before measuring at $345 \mathrm{~nm}$ using a Synergy HTX (Bio-Tek, Winooski, VT, USA) reader. In a blank control group, $3 \mathrm{~mL}$ of $6 \mathrm{M} \mathrm{HCl}$ was added before the addition of TNBS solution. The cross-linking degree was estimated using the following equation:

$$
\text { Cross-linking degree }(\%)=\left[1-\left(O D_{c}-O D_{b}\right) /\left(O D_{n}-O D_{b}\right)\right] \times 100
$$

where $O D_{c}$ is the absorbance of scaffolds, $O D_{b}$ is the absorbance of the blank control group, and $O D_{n}$ is the absorbance of uncross-linked scaffolds.

\subsubsection{Enzymatic Degradation}

The biodegradation property of scaffolds was investigated according to the method from the previous report [26]. Briefly, weighed scaffolds $\left(W_{0}\right)$ were incubated in $1.5 \mathrm{~mL}$ of $0.1 \mathrm{M}$ phosphate buffer $\mathrm{pH} 7.4$ containing $60 \mu \mathrm{g} / \mathrm{mL}$ collagenase $\left(16\right.$ units) at $37{ }^{\circ} \mathrm{C}$. After a fixed time, the scaffolds were taken out, washed with distilled water, lyophilized, and weighed $\left(W_{1}\right)$. The enzymatic degradation ratio $W_{D}(\%)$ was determined using the following equation:

$$
W_{D}(\%)=\left[\left(W_{0}-W_{1}\right) / W_{0}\right] \times 100
$$

\subsubsection{Antioxidant Capacity}

$\mathrm{ABTS}^{+}$and DPPH radical scavenging capacity of scaffolds was used to determine the antioxidant capacity of scaffolds. For $\mathrm{ABTS}^{+}$assay, $7.4 \mathrm{mM} \mathrm{ABTS}^{+}$and $2.6 \mathrm{mM}$ potassium persulfate $\left(\mathrm{K}_{2} \mathrm{~S}_{2} \mathrm{O}_{8}\right)$ stock solutions were prepared separately. An equal volume of the two stock solutions was mixed and stand for $16 \mathrm{~h}$ in the absence of light at room temperature 
to form $\mathrm{ABTS}^{+}$fresh solution. The fresh solution was diluted with methanol to get an absorbance of 0.7 at $734 \mathrm{~nm}$. Then, $100 \mu \mathrm{L}$ of diluted ABTS $^{+}$solution was mixed with $100 \mu \mathrm{L}$ sample solution containing $1 \mathrm{mg} / \mathrm{mL}$ uncross-linked scaffolds in deionized water. The resulting mixture was incubated for $5 \mathrm{~min}$ at room temperature in a dark place. The measurement was done at $734 \mathrm{~nm}$ using a Synergy HTX reader (BioTek Instruments, Inc., Winooski, VT, USA). The control test was carried out in the same manner but $100 \mu \mathrm{L}$ of methanol was used instead of $100 \mu \mathrm{L}$ of the sample solution. The $\mathrm{ABTS}^{+}$radical scavenging (\%) was calculated as follows:

$$
\mathrm{ABTS}^{+} \text {radical scavenging }(\%)=\left(A_{c}-A_{s}\right) / A_{c} \times 100
$$

where $A_{c}$ is the absorbance of the control and $A_{s}$ is the absorbance of the samples.

For DPPH assay, $500 \mathrm{mM}$ DPPH stock solution was diluted using methanol to obtain the absorbance value 1.4 at $517 \mathrm{~nm}$ using a Synergy HTX reader. Then, $100 \mu \mathrm{L}$ diluted DPPH solution was mixed with $100 \mu \mathrm{L}$ of a sample solution containing $1 \mathrm{mg} / \mathrm{mL}$ uncross-linked scaffolds in deionized water. The mixture was placed in the dark at room temperature for $30 \mathrm{~min}$. The absorbance was measured at $517 \mathrm{~nm}$. The control test was done under the same conditions using $100 \mu \mathrm{L}$ methanol instead of $100 \mu \mathrm{L}$ of the sample solution. DPPH radical scavenging $(\%)$ was calculated as follows:

$$
\text { DPPH radical scavenging }(\%)=\left(A_{c}-A_{s}\right) / A_{c} \times 100
$$

where $A_{c}$ is the absorbance of the control and $A_{s}$ is the absorbance of samples.

\subsubsection{In Vitro Blood Clotting Assay}

The determination of the blood clotting capacity of the sponges was examined according to the method reported by [32]. Uncross-linked sponges in deionized water $\left(1 \mathrm{mg} \mathrm{mL}^{-1}\right)$ was used in an activated partial thromboplastin time test (aPTT).

Partial thromboplastin with activator, calcium chloride $(0.025 \mathrm{M})$, and sample solutions were pre-warmed at $37^{\circ} \mathrm{C}$ in a water bath before use. For the control test, the test tube containing $33 \mu \mathrm{L}$ deionized water was mixed with $50 \mu \mathrm{L}$ of human plasma. The mixture was then incubated at $37^{\circ} \mathrm{C}$ for $3 \mathrm{~min}$ before adding $50 \mu \mathrm{L}$ of the aPTT solution and rapidly mixed. After incubating for another $3 \mathrm{~min}$ at $37^{\circ} \mathrm{C}$, the content was added with $50 \mu \mathrm{L}$ of the pre-warmed $\mathrm{CaCl}_{2}$ solution while simultaneously starting a timer. Then, the test tube was gently tilted back and forth. The clotting time was immediately recorded as the first clot formed. For the tests of scaffolds, the test tube contained $33 \mu \mathrm{L}$ of pre-warmed sample solution instead of deionized water. The blood clotting activity tests were performed in triplicate.

\subsection{Statistical Analysis}

Data were analyzed by one-way analysis of variance with a confidence level of $95 \%$ and $p<0.05$ considered as statistical difference. Analyzed data were presented as means \pm $\mathrm{SD}$ obtained from three independent experiments.

\section{Conclusions}

In the present study, it is hypothesized that the scaffolds made from low MW collagen and alginate could possess high bioactivity and flexible structure that could have close contact with the wound sites and could lessen discomfort such as hurt feelings when the scaffolds are applied on patients. Indeed, the prepared scaffolds showed a highly soft structure and promising bioactivity including antioxidant and coagulant activities; therefore, the results meet the goals of the study. Although there was no significant difference in antioxidant capacity between scaffolds, there were trends that, first, scaffolds containing low MW collagen (C6-A250) improved free radical scavenging activity as compared with those containing high MW collagen (C25-A250), and second, scaffolds containing modified alginate (C25-A125, C25-A63, and C25-A21) tended to increase radical scavenging activity 
when the treating temperature increased. In another word, the antioxidant capacity of scaffolds tends to increase with the decrease in the MW of biopolymers due to more functional groups such as hydroxyl, carbonyl, and carboxyl groups that contain more electron donors are produced. Scaffolds containing low MW alginate (C25-A63, C25-A21) exhibited significant coagulant capacity as compared with those containing high MW alginate (C6-A250, C25-A250, C25-A125). However, the difference in MW of collagen did not significantly influence on the coagulant activity (C6-A250 and C25-A250).

All the scaffolds possessed a highly porous structure with approximately $93 \%$, thus they meet the requirement of the desired scaffold. Besides, the prepared scaffolds, except C25-A63, showed a high cross-linking degree with greater than 50\%. Consequently, these scaffolds exhibited a low weight loss and high water-retention capacity, especially C25-A63. On the other hand, C6-A250 had poor physicochemical stability with the highest weight loss and enzymatic degradation, hence, this scaffold might have no practical applications. For further studies, the improvement of physicochemical stability of these scaffolds using bio-conjugation with phenolic compounds should be considered.

Author Contributions: Conceptualization, T.C.H. and B.-S.C.; methodology, T.C.H.; validation, T.C.H. and J.-S.P.; formal analysis, T.C.H.; investigation, T.C.H., H.L., S.-Y.K., and J.-S.P.; resources, B.-S.C., J.-S.L., S.-J.K., M.-H.C., and S.Y.N.; data curation, T.C.H. and J.-S.P.; writing-original draft preparation, T.C.H.; writing-review and editing, T.C.H.; visualization; supervision, B.-S.C.; project administration, B.-S.C.; funding acquisition, B.-S.C. All authors have read and agreed to the published version of the manuscript.

Funding: This work was funded by the Technology Development Program (S2899389) and the APC was funded by the Ministry of SMEs and Startups (MSS, Korea).

Institutional Review Board Statement: Ethical review and approval were waived for this study, because human plasma and aPTT reagent were obtained from Thermo Fisher Scientific, Pittsburgh, PA, USA.

Informed Consent Statement: Patient consent was waived because human plasma and aPTT reagent were obtained from Thermo Fisher Scientific, Pittsburgh, PA, USA.

Data Availability Statement: Not applicable.

Conflicts of Interest: The authors declare no conflict of interest.

\section{References}

1. Avila Rodríguez, M.I.; Rodríguez Barroso, L.G.; Sánchez, M.L. Collagen: A review on its sources and potential cosmetic applications. J. Cosmet. Dermatol. 2018, 17, 20-26. [CrossRef] [PubMed]

2. Saito, M.; Kiyose, C.; Higuchi, T.; Uchida, N.; Suzuki, H. Effect of collagen hydrolysates from salmon and trout skins on the lipid profile in rats. J. Agric. Food Chem. 2009, 57, 10477-10482. [CrossRef] [PubMed]

3. Gu, L.; Shan, T.; Ma, Y.-x.; Tay, F.R.; Niu, L. Novel Biomedical Applications of Crosslinked Collagen. Trends Biotechnol. 2019, 37, 464-491. [CrossRef] [PubMed]

4. Liu, Y.; Ma, L.; Gao, C. Facile fabrication of the glutaraldehyde cross-linked collagen/chitosan porous scaffold for skin tissue engineering. Mater. Sci. Eng. C 2012, 32, 2361-2366. [CrossRef]

5. Chandika, P.; Ko, S.-C.; Oh, G.-W.; Heo, S.-Y.; Nguyen, V.-T.; Jeon, Y.-J.; Lee, B.; Jang, C.H.; Kim, G.; Park, W.S.; et al. Fish collagen/alginate/chitooligosaccharides integrated scaffold for skin tissue regeneration application. Int. J. Biol. Macromol. 2015, 81, 504-513. [CrossRef]

6. Sang, L.; Luo, D.; Xu, S.; Wang, X.; Li, X. Fabrication and evaluation of biomimetic scaffolds by using collagen-alginate fibrillar gels for potential tissue engineering applications. Mater. Sci. Eng. C 2011, 31, 262-271. [CrossRef]

7. Karri, V.V.S.R.; Kuppusamy, G.; Talluri, S.V.; Mannemala, S.S.; Kollipara, R.; Wadhwani, A.D.; Mulukutla, S.; Raju, K.R.S.; Malayandi, R. Curcumin loaded chitosan nanoparticles impregnated into collagen-alginate scaffolds for diabetic wound healing. Int. J. Biol. Macromol. 2016, 93, 1519-1529. [CrossRef]

8. Sun, L.; Li, B.; Jiang, D.; Hou, H. Nile tilapia skin collagen sponge modified with chemical cross-linkers as a biomedical hemostatic material. Colloids Surf. B Biointerfaces 2017, 159, 89-96. [CrossRef]

9. Ma, L.; Gao, C.; Mao, Z.; Zhou, J.; Shen, J.; Hu, X.; Han, C. Collagen/chitosan porous scaffolds with improved biostability for skin tissue engineering. Biomaterials 2003, 24, 4833-4841. [CrossRef] 
10. Ferrario, C.; Rusconi, F.; Pulaj, A.; Macchi, R.; Landini, P.; Paroni, M.; Colombo, G.; Martinello, T.; Melotti, L.; Gomiero, C. From food waste to innovative biomaterial: Sea urchin-derived collagen for applications in skin regenerative medicine. Mar. Drugs 2020, 18, 414. [CrossRef]

11. Hong, H.; Fan, H.; Chalamaiah, M.; Wu, J. Preparation of low-molecular-weight, collagen hydrolysates (peptides): Current progress, challenges, and future perspectives. Food Chem. 2019, 301, 125222. [CrossRef] [PubMed]

12. Wu, X.; Black, L.; Santacana-Laffitte, G.; Patrick, J.; Charles, W. Preparation and assessment of glutaraldehyde-crosslinked collagen-chitosan hydrogels for adipose tissue engineering. J. Biomed. Mater. Res. Part A 2007, 81A, 59-65. [CrossRef] [PubMed]

13. Aida, T.M.; Yamagata, T.; Watanabe, M.; Smith, R.L., Jr. Depolymerization of sodium alginate under hydrothermal conditions. Carbohydr. Polym. 2010, 80, 296-302. [CrossRef]

14. Li, X.; Xu, A.; Xie, H.; Yu, W.; Xie, W.; Ma, X. Preparation of low molecular weight alginate by hydrogen peroxide depolymerization for tissue engineering. Carbohydr. Polym. 2010, 79, 660-664. [CrossRef]

15. Ding, W.; Zhou, J.; Zeng, Y.; Wang, Y.-n.; Shi, B. Preparation of oxidized sodium alginate with different molecular weights and its application for crosslinking collagen fiber. Carbohydr. Polym. 2017, 157, 1650-1656. [CrossRef]

16. Murphy, E.C.; Friedman, A.J. Hydrogen peroxide and cutaneous biology: Translational applications, benefits, and risks. J. Am. Acad. Dermatol. 2019, 81, 1379-1386. [CrossRef]

17. Nkurunziza, D.; Ho, T.C.; Protzman, R.A.; Cho, Y.-J.; Getachew, A.T.; Lee, H.-J.; Chun, B.S. Pressurized hot water crosslinking of gelatin-alginate for the enhancement of spent coffee oil emulsion stability. J. Supercrit. Fluids 2021, 169, 105120. [CrossRef]

18. Pieper, J.; Hafmans, T.; Veerkamp, J.; Van Kuppevelt, T. Development of tailor-made collagen-glycosaminoglycan matrices: EDC/NHS crosslinking, and ultrastructural aspects. Biomaterials 2000, 21, 581-593. [CrossRef]

19. Olde Damink, L.H.H.; Dijkstra, P.J.; Van Luyn, M.J.A.; Van Wachem, P.B.; Nieuwenhuis, P.; Feijen, J. Glutaraldehyde as a crosslinking agent for collagen-based biomaterials. J. Mater. Sci. Mater. Med. 1995, 6, 460-472. [CrossRef]

20. Yan, L.-P.; Wang, Y.-J.; Ren, L.; Wu, G.; Caridade, S.G.; Fan, J.-B.; Wang, L.-Y.; Ji, P.-H.; Oliveira, J.M.; Oliveira, J.T.; et al. Genipin-cross-linked collagen/chitosan biomimetic scaffolds for articular cartilage tissue engineering applications. J. Biomed. Mater. Res. Part A 2010, 95A, 465-475. [CrossRef]

21. Reddy, N.; Reddy, R.; Jiang, Q. Crosslinking biopolymers for biomedical applications. Trends Biotechnol. 2015, 33, 362-369. [CrossRef] [PubMed]

22. Umashankar, P.; Mohanan, P.; Kumari, T. Glutaraldehyde treatment elicits toxic response compared to decellularization in bovine pericardium. Toxicol. Int. 2012, 19, 51. [CrossRef] [PubMed]

23. Chandra Roy, V.; Ho, T.C.; Lee, H.-J.; Park, J.-S.; Nam, S.Y.; Lee, H.; Getachew, A.T.; Chun, B.-S. Extraction of astaxanthin using ultrasound-assisted natural deep eutectic solvents from shrimp wastes and its application in bioactive films. J. Clean. Prod. 2021, 284, 125417. [CrossRef]

24. Liu, M.; Shen, Y.; Ao, P.; Dai, L.; Liu, Z.; Zhou, C. The improvement of hemostatic and wound healing property of chitosan by halloysite nanotubes. RSC Adv. 2014, 4, 23540-23553. [CrossRef]

25. Sun, L.; Li, B.; Yao, D.; Song, W.; Hou, H. Effects of cross-linking on mechanical, biological properties and biodegradation behavior of Nile tilapia skin collagen sponge as a biomedical material. J. Mech. Behav. Biomed. Mater. 2018, 80, 51-58. [CrossRef]

26. Choi, Y.S.; Hong, S.R.; Lee, Y.M.; Song, K.W.; Park, M.H.; Nam, Y.S. Study on gelatin-containing artificial skin: I. Preparation and characteristics of novel gelatin-alginate sponge. Biomaterials 1999, 20, 409-417. [CrossRef]

27. Khiari, Z.; Ndagijimana, M.; Betti, M. Low molecular weight bioactive peptides derived from the enzymatic hydrolysis of collagen after isoelectric solubilization/precipitation process of turkey by-products. Poult. Sci. 2014, 93, 2347-2362. [CrossRef]

28. Chung, L.; Dinakarpandian, D.; Yoshida, N.; Lauer-Fields, J.L.; Fields, G.B.; Visse, R.; Nagase, H. Collagenase unwinds triplehelical collagen prior to peptide bond hydrolysis. EMBO J. 2004, 23, 3020-3030. [CrossRef]

29. Fan, L.; Peng, M.; Zhou, X.; Wu, H.; Hu, J.; Xie, W.; Liu, S. Modification of carboxymethyl cellulose grafted with collagen peptide and its antioxidant activity. Carbohydr. Polym. 2014, 112, 32-38. [CrossRef]

30. Kelishomi, Z.H.; Goliaei, B.; Mahdavi, H.; Nikoofar, A.; Rahimi, M.; Moosavi-Movahedi, A.A.; Mamashli, F.; Bigdeli, B. Antioxidant activity of low molecular weight alginate produced by thermal treatment. Food Chem. 2016, 196, 897-902. [CrossRef]

31. Tan, H.; Wu, J.; Lao, L.; Gao, C. Gelatin/chitosan/hyaluronan scaffold integrated with PLGA microspheres for cartilage tissue engineering. Acta Biomater. 2009, 5, 328-337. [CrossRef] [PubMed]

32. Pawlaczyk, I.; Capek, P.; Czerchawski, L.; Bijak, J.; Lewik-Tsirigotis, M.; Pliszczak-Król, A.; Gancarz, R. An anticoagulant effect and chemical characterization of Lythrum salicaria L. glycoconjugates. Carbohydr. Polym. 2011, 86, 277-284. [CrossRef] 